\title{
AN AES STUDY OF THE SURFACE COMPOSITION OF COBALT FERRITES
}

\author{
F. GARBASSI, G. PETRINI and L. POZZI \\ Montedison S.p.A., "G.Donegani”' Research Institute, I-28100 Novara, Italy \\ G. BENEDEK \\ Gruppo Nazionale di Struttura della Materia del CNR, Via Celoria 16, Milano, Italy
}

and

G. PARRAVANO

Department of Chemical Engineering, University of Michigan, Ann Arbor, Michigan 48109, USA

A series of cobalt ferrite samples, $\mathrm{Co}_{1-y} \mathrm{Fe}_{2+y} \mathrm{O}_{4}$, where $-0.1 \leqslant y \leqslant 0.1$, was examined by AES. A remarkable Fe surface enrichment was observed near the stoichiometric composition for $y$ both positive and negative, and found to be in quite good agreennent with theoretical calculations. The submission of samples to various treatments, at different temperatures and gas atmospheres, produced changes in the surface composition, in a fashion associated with the oxygen concentration both in gas and solid phase.

\section{Introduction}

The chemical composition, stability ranges and defect structure of cobalt ferrite, $\mathrm{CoFe}_{2} \mathrm{O}_{4}$, have been extensively studied in recent years [1]. These studies have stimulated investigations on the surface reactivity and catalytic properties of cobalt ferrite [2,3]. In the latter studies a decisive factor for obtaining meaningful kinetic correlations was the composition of the rcacting surface, which could be inferred only from the bulk composition. With the introduction of Auger electron spectroscopy (AES) into surface studies, the composition of surface layers may be obtained directly. Consequently, we have submitted a series of non-stoichiometric cobalt ferrite samples, $\mathrm{Co}_{1-y} \mathrm{Fe}_{2+y} \mathrm{O}_{4}$, already used in the earlier experiments, to AES analysis. The results of these experiments, together with observations on the influence of thermal treatments under various gas atmospheres are collected in the present communication and interpreted on the basis of the thermodynamic theory of surface segregation [4]. 


\section{Experimental}

Cobalt ferrite samples were prepared by wet milling $\mathrm{Fe}_{2} \mathrm{O}_{3}$ and $\mathrm{CoCO}_{3}$ and firing in air in a furnace at $1340 \mathrm{~K}$ for $12 \mathrm{~h}$ [2]. Cooling to $1090 \mathrm{~K}$ was carried out in the furnace, followed by an air quench. Bulk compositions were measured by X-ray fluorescence spectrometry, while the homogeneity of the spinel phase was checked by X-ray diffraction. The AES analyses were performed in a commercial system (Physical Electronics Ind., Eden Prairie, Minn.), equipped with a cylindrical mirror analyzer, a $5 \mathrm{keV}$ integral electron gun, a $1 \mathrm{keV}$ sputter-ion gun and an electron bombardment heater. The base pressure was about $1.33 \times 10^{-7} \mathrm{~Pa}$. All the Auger measurements were done on oxide grains of suitable dimensions, at normal incidence and under the following experimental conditions: beam current $50 \mu \mathrm{A}$; primary energy $3 \mathrm{keV}$; modulation voltage $3 \mathrm{~V}$; time constant $0.001 \mathrm{sec}$. Charge effects caused large shifts in the scan energy. However, due to the relative simplicity of the spectra, they could be adjusted easily to the correct position on the energy scale. Heat treatments on cobalt ferrite samples were carried out in Pt crucibles set in a tubular furnace, with a gas flow of about $51 / \mathrm{h}$. Samples were cooled in the same atmosphere.

\section{Results}

Since the usual contaminants $(\mathrm{Cl}, \mathrm{C}, \mathrm{S})$ were present in relatively small amounts (up to $5 \%$ ), a preliminary cleaning of the surfaces was not considered necessary, nor were the former taken into account in the calculation of surface compositions. The low energy $\mathrm{M}_{2,3} \mathbf{M}_{4,5} \mathrm{M}_{4,5}$ peaks of $\mathrm{Fe}$ and $\mathrm{Co}$ were sometimes unresolved and masked by charge effects, consequently the $\mathrm{L}_{3} \mathrm{M}_{2,3} \mathrm{M}_{2,3}$ peak of $\mathrm{Fe}$ (at $600 \mathrm{eV}$ ) and the $L_{3} M_{4,5} M_{4,5}$ peak to $\mathrm{Co}$ (at $775 \mathrm{eV}$ ) were chosen for the analysis, together with the $\mathrm{KL}_{2,3} \mathrm{~L}_{2,3}$ peak of $\mathrm{O}$. Surface compositions were determined by the method of elemental sensitivity factors [5]. Values of $1,0.31$ and 0.60 were used for the sensitivity factors of $\mathrm{O}, \mathrm{Fe}$ and $\mathrm{Co}$ respectively. The above values were determined with the aid of AES spectra of sputter-etched samples. Generally, 50 to $90 \mathrm{~min}$ at $1 \mathrm{keV}$ and $8 \mu \mathrm{A}$ of ion current, with an Ar pressure of $6.5 \times 10^{-3} \mathrm{~Pa}$ were necessary to achieve a constant value of the metal peaks ratios. A selective enrichment induced by the sputtering can be excluded since the Co and Fe sputter yields are similar [6]. Some examples of depth profiles obtained in this way are presented in fig. 1. The sensitivity factor values obtained from the standard spectra [7] were slightly corrected by making the $\mathrm{Co} / \mathrm{Fe}$ ratio measured after sputtering to reproduce the respective bulk ratio, and by adjusting the oxygen-cation ratio of the stoichiometric sample, which remains constant during sputtering, to the bulk value 1.33. By comparison with Auger spectra of $\mathrm{Fe}_{3} \mathrm{O}_{4}$ and $\mathrm{Co}_{3} \mathrm{O}_{4}$, however, the oxygen surface concentrations can be considered affected by an error not larger than $20 \%$. The overall error in the $\mathrm{Co} / \mathrm{Fe}$ ratio was estimated to be $\pm 5 \%$, this value including possible sample inhomogeneity. 


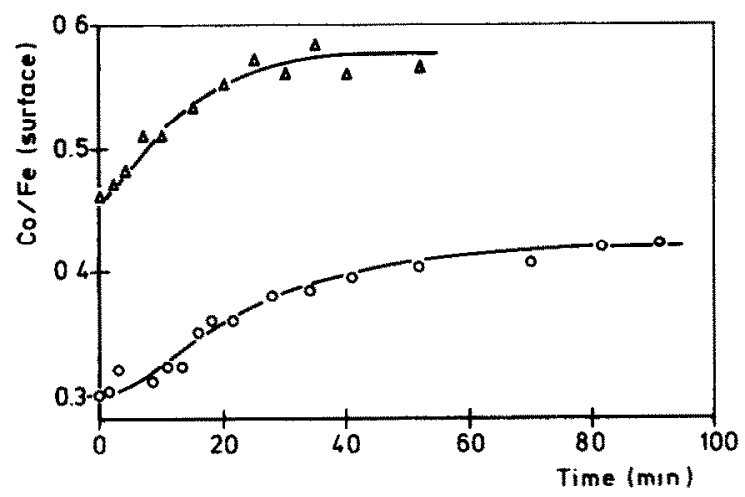

Fig. 1. Composition depth profile of cobalt ferrite, versus sputtering time. Open circles and triangles are referred to $\mathrm{Co} / \mathrm{Fe}$ bulk values of 0.43 and 0.575 respectively.

Bulk and surface compositions of the untreated samples are reported in table 1 and the corresponding surface versus bulk $\mathrm{Co} / \mathrm{Fe}$ ratios are shown in fig. $2 \mathrm{a}$. The surface values represent averages of several analyses (up to six) performed on different pellets of the same sample. The experimental surface compositions obtained after sputtering are reported in table 2, together with those measured after various thermal treatments, and plotted in fig. $2 \mathrm{~b}$ versus bulk $\mathrm{Co} / \mathrm{Fe}$ ratios. In fig. $2 \mathrm{c}$, the values of the $\mathrm{Co} / \mathrm{Fe}$ ratio obtained after a thermal treatment in $\mathrm{N}_{2}$ at $1273 \mathrm{~K}$ for $6.5 \mathrm{~h}$ are reported. Rather similar results, as shown in fig. $2 \mathrm{~d}$, were found using He instead of $\mathrm{N}_{2}$. Another series of samples was heated at $1073 \mathrm{~K}$ for half an hour in the UHV chamber at a residual pressure of $1.33 \times 10^{-7} \mathrm{~Pa}$, and a remarkable increase in the Co surface concentration was found (fig. 2e).

Whenever possible, X-ray diffraction analyses were performed on the samples which underwent the thermal treatments. The results of the X-ray analyses are sum-

Table 1

Surface composition of cobalt ferrite

\begin{tabular}{|c|c|c|c|c|}
\hline \multicolumn{3}{|c|}{ Surface composition $(\%)$} & \multicolumn{2}{|l|}{$\mathrm{Co} / \mathrm{Fi}^{\mathrm{a}}$} \\
\hline o & $\mathrm{Fe}$ & $\mathrm{Co}$ & (Surface) & (Bulk) \\
\hline 59.2 & 31.5 & 9.3 & 0.30 & 0.43 \\
\hline 57.3 & 28.9 & 13.8 & 0.48 & 0.455 \\
\hline 57.5 & 28.3 & 14.2 & 0.50 & 0.495 \\
\hline 57.3 & 28.0 & 14.7 & 0.52 & 0.505 \\
\hline 60.5 & 26.9 & 12.6 & 0.47 & 0.535 \\
\hline 59.8 & 26.2 & 14.0 & 0.53 & 0.575 \\
\hline
\end{tabular}

a Atomic ratio. 


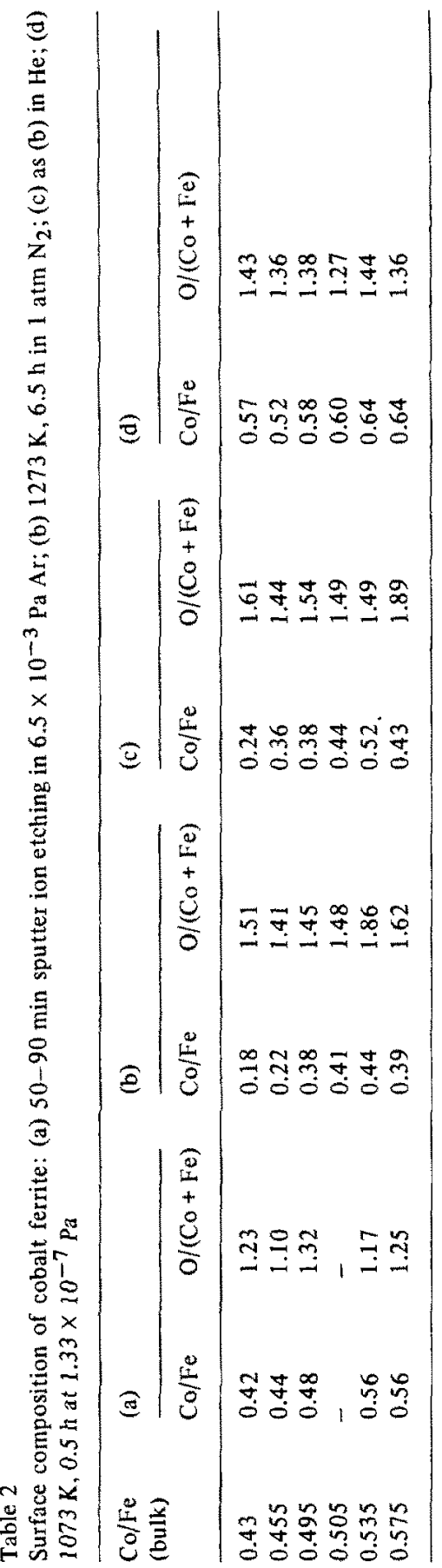




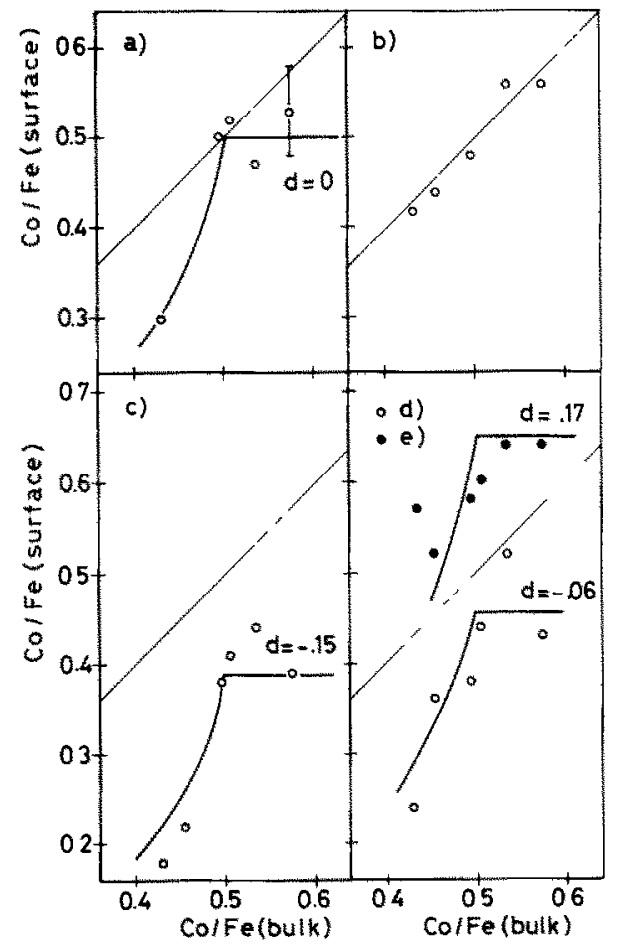

Fig. 2. Co/Fe surface versus bulk ratio in cobalt ferrite samples. (a) Untreated samples. (b) $50-$ 90 min sputter ion etching in $6.5 \times 10^{-3} \mathrm{~Pa} \mathrm{Ar}$. (c) $1273 \mathrm{~K} .6 .5 \mathrm{~h}$ in $1 \mathrm{~atm} \mathrm{~N}_{2}$. (d) as (c), in He. (e) $1073 \mathrm{~K}, 0.5 \mathrm{~h}$ at $1.33 \times 10^{-7} \mathrm{~Pa}$. Curves represent the results of theoretical calculations, assuming the $d$ values indicated (for the definition of $d$, see text).

Table 3

$\mathrm{X}$-ray diffraction of cobalt ferrite after thermal treatments; phases outer than $\mathrm{Col}_{2} \mathrm{e}_{2} \mathrm{O}_{4}$ are indicated: (a) after heating to $1273 \mathrm{~K}$ for $6.5 \mathrm{~h}$ in $1 \mathrm{~atm} \mathrm{~N}_{2}$; (b) as (a) in He atmosphere; (c) after heating to $1073 \mathrm{~K}$ for $0.5 \mathrm{~h}$ at $1.33 \times 10^{-7} \mathrm{~Pa}$

\begin{tabular}{|c|c|c|c|}
\hline Co/fe (bulk) & (a) & (b) & (c) \\
\hline 0.43 & - & & $1 \% \mathrm{CoO}$ \\
\hline 0.455 & $\ldots$ & $-\cdots$ & n.d. \\
\hline 0.495 & $2-3 \% \mathrm{CoO}$ & $\begin{array}{l}1-2 \% \mathrm{CoO} \\
1 \% \mathrm{Co}_{3} \mathrm{O}_{4}\end{array}$ & n.d. \\
\hline 0.505 & - & $2 \pi \mathrm{CoO}$ & $1 / \% \mathrm{COO}$ \\
\hline 0.535 & $1-2 \% \mathrm{CoO}$ & $\cdots$ & $2-3 \% \mathrm{CoO}$ \\
\hline 0.575 & n.d. & $\begin{array}{l}3-5 \% \mathrm{CoO} \\
1 \% \mathrm{Co}_{3} \mathrm{O}_{4}\end{array}$ & $4-6 \% \mathrm{CoO}$ \\
\hline
\end{tabular}




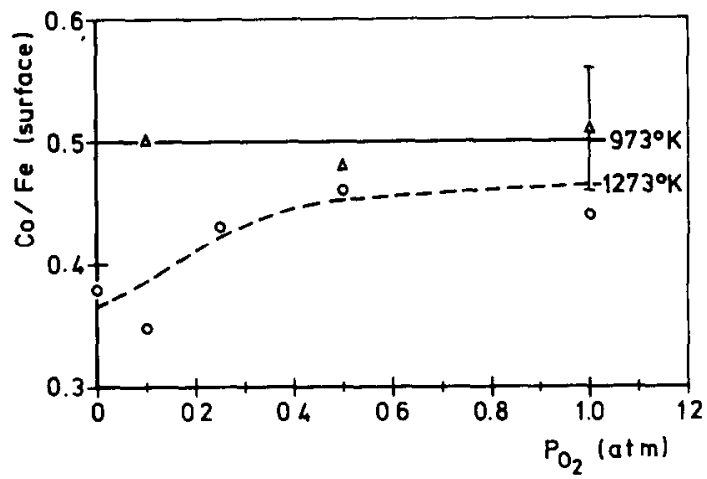

Fig. 3. $\mathrm{Co} / \mathrm{Fe}$ ratio versus oxygen partial pressure, $p \mathrm{O}_{2}$, during pretreatment at high temperatures. $\mathrm{Co} / \mathrm{Fe}$ (bulk) $=0.495 ;$ treatment time $6.5 \mathrm{~h}$.

marized in table 3. In most of the samples, $\mathrm{CoO}$ as a separate phase was determined in amounts increasing with the bulk Co concentration. Treatment in an $\mathrm{O}_{2}$ atmosphere was performed on a sample with a bulk $\mathrm{Co} / \mathrm{Fe}$ ratio of 0.495 with $\mathrm{pO}_{2}$ vary. ing from 0.1 to $1 \mathrm{~atm}$ (He was the carrier gas) at 973 and $1273 \mathrm{~K}$. The results are shown in fig. 3. At $973 \mathrm{~K}$ no variation of the $\mathrm{Co} / \mathrm{Fe}$ ratio was found, while at $1273 \mathrm{~K}$ there was a gradual increase of the ratio with increasing $p \mathrm{O}_{2}$. In this sample, no separate $\mathrm{CoO}$ phase was observed by $\mathrm{X}$-ray diffraction.

\section{Discussion}

A general feature of the untreated samples (fig. 2a) is the surface iron enrichment, with respect to the bulk composition, both for samples having a $\mathrm{Co} / \mathrm{Fe}$ ratio in defect or in excess as regards the stoichiometric composition. After a prolongated etching, the surface $\mathrm{Co} / \mathrm{Fe}$ ratios converge to the bulk values (fig. 2b). These results were used to check the reliability of the sensitivity factor, while the depth profile shapes (fig. 1) indicated a gradual composition change.

In the treated samples, where a surface oxygen enrichment was always found (table 2), an increased iron enrichment is observed (figs. $2 \mathrm{c}$ and $2 \mathrm{~d}$ ). However, the surface cleaning by heating the samples in vacuo at $1073 \mathrm{~K}$ (fig. 2e) yields a remarkable cobalt enrichment of the surface, in spite of the fact that a surface oxygen excess is still found.

The correlation between surface oxygen amount and cation distribution was investigated on the basis of equilibrium thermodynamics.

Oxygen exchange between surface and gas phase takes place as both lattice oxygen loss and chemisorption. In the first process two electrons per oxygen atom are left in the crystal and captured by the trivalent cations. In the second process, molecular oxygen is assumed to be chemisorbed as $\mathrm{O}_{2}^{-}$, the additional electron 
being provided by divalent cations. Hence we write the surface composition as

$$
\begin{array}{ll}
\mathrm{Fe}^{3+}\left(\mathrm{Co}_{1-y_{\mathrm{s}}}^{2+} \mathrm{Fe}_{y_{\mathrm{s}}+d}^{2+} \mathrm{Fe}_{1-d}^{3+}\right) \mathrm{O}_{4-b}^{2-}\left(\mathrm{O}_{2}^{-}\right)_{c} & \left(y_{s}>0\right), \\
\mathrm{Fe}^{3+}\left(\mathrm{Co}_{1+d}^{2+} \mathrm{Co}_{-y_{\mathrm{s}}-d}^{3+} \mathrm{Fe}_{1+y_{\mathrm{s}}}^{3+}\right) \mathrm{O}_{4-b}^{2}\left(\mathrm{O}_{2}^{-}\right)_{c} & \left(y_{\mathrm{s}}<0\right),
\end{array}
$$

where $d \equiv 2 b-c$ is either positive or negative; $b$ and $c$ are functions of gas-phase pressure and temperature. The bulk compoistion is given by (1) as well, with $b, c=$ 0 and $y$ instead of $y_{s}$.

The equilibrium condition between bulk and surface reads for both $y>0$ and $y<0$

$\frac{1-\left|y_{\mathrm{s}}\right|}{1-|y|} \frac{y}{y_{\mathrm{s}}+d}=\exp \left(\Delta^{(i)} / k T\right)$

where $\Delta^{(2)}$ and $\Delta^{(3)}$ are the changes of the standard chemical potential for the bulksurface exchange of divalent cations $(y>0)$, and trivalent cations $(y<0)$, respectively. From a theoretical calculation [4] we found $\Delta^{(2)}=-0.142 \mathrm{eV}$ and $\Delta^{(3)}=$ $0.682 \mathrm{eV}$. The calculated curve $\rho_{\mathrm{s}}=\left(1-y_{\mathrm{s}}\right) /\left(2+y_{\mathrm{s}}\right)$ versus $\rho=(1-y) /(2+y)$ for $b=c=0$ compares reasonably well with the untrated sample experimental points (fig. 2a). In treated samples, the experimental average values of the oxygen-tocation ratio $\frac{1}{3}(4-b+2 c)$ are 1.56 for $\mathrm{N}_{2}$ flux treatment and 1.58 for He flux treatment, against 1.33 for the ideal case. Hence we have an oxygen excess at the surface due to chemisorption. A reasonable fit of the two above sets of experimental data is obtained with $d=0.15$ and $d=-0.06$, respectively (fig. $2 \mathrm{c}$ and $2 \mathrm{~d}$ ). Combining these values with those of the oxygen-to-cation ratios we find a small number (few percents) of surface oxygen vacancies, largely compensated by chemisorption: we get $b=0.13, c=0.40$ for $\mathrm{N}_{2}$ treated samples and $b=0.21, c=0.47$ for He treated samples.

For the last set of data, those obtained after a UHV treatment at high temperature, the average oxygen-to-cation ratio reduces to 1.38 , and cobalt excess always occurs at the surfacc. Now, the theoretical fitting is quite poor (fig. 2e). Nevertheless we obtain $b=0.16$, a value quite close to those found in treated samples, and $c=0.15$, which is instead quite lower than the values found above, because of the surface cleaning. It is interesting to remark that now $c \simeq b$, which means that at the surface we have as many chemisorbed oxygen molecules as vacant oxygen lattice sites. This could be interpreted as due to the fact that oxygen molecules chemisorbed at vacant oxygen lattice sites are tightly bound, in such a way they survive to UHV heating treatment.

Finally, the X-ray diffraction data given in table 3 are in agreement with the known features of the $\mathrm{Fe}-\mathrm{Co}-\mathrm{O}$ phase diagram [1] where $p_{0}$ and $T$ necessary to obtain a single phase with given $\mathrm{Co} / \mathrm{Fe}$ ratio can be predicted; fig. 3 suggests that there is a connection also between $T, p_{0}$ and surface $\mathrm{Co} / \mathrm{Fe}$ ratio. 


\section{References}

[1] W. Müller and H. Schmalzried, Rer. Bunsenges. Physik. Chem. 68 (1964) 270;

J.D. Tretjakow and H. Schmalzried, Ber. Bunsenges. Physik. Chem., 69 (1965) 396.

[2] R.G. Squires and G. Parravano, J. Catalysis 2 (1963) 324.

[3] G. Parravano, in: Proc. 4 th Intern. Congr. on Catalysis, Moscow, 1968, vol. I (Akademiai Kiado, Budapest, 1971) p. 149.

[4] G. Benedek, F. Garbassi, G. Petrini and G. Parravano, submitted to J. Phys. Chem. Solids.

[5] P.W. Palmberg, Anal. Chem. 45 (1973) 549A.

[6] N. Laegreid and G.K. Wehner, J. Appl. Phys. 32 (1961) 365.

[7] P.W. Palmberg, G.E. Riach, R.E. Weber and N.C. MacDonald, Handbook of Auger Electron Spectroscopy (Edina, 1972). 